\title{
Prevalence of Pediculosis and Its Predictors among Urban Primary School Children in Kuantan, Pahang
}

Muhammad Rusyaidi Azali, Nor Faiza Mohd Tohit, Razman Mohd Rus

Department of Community Medicine, Kulliyah of Medicine International Islamic University Malaysia

Introduction: Pediculosis capitis among primary school children is always known as the problem of the lower socio-economic class and rural communities. It carries significant consequences to the school children and caregivers. Limited studies have been conducted among the urban populations. Thus, this study aims to investigate the prevalence and predictors of Pediculosis capitis among Urban primary school children in Kuantan. Materials and method: An analytical cross-sectional study using cluster random sampling was carried out in Kuantan, Pahang, Malaysia. A selfadministered validated questionnaire was issued to the participants with purpose to collect socio-demographic data related to age, gender and factors that associated with head lice infestations among primary school children from standard one to six. It was then followed by hair and scalp examination by a well-trained examiners to check the infestation status. The results were analyzed using the chi-squared test and logistic regression analysis. Results: A total of 1347 students from 5 schools were included in this study. Majority of them were males (53.6\%), Malays $(61.0 \%)$, household income between RM1000-RM2999 (32.1\%). The overall prevalence was 9.1\% $(\mathrm{n}=122)$. Multivariate analysis showed that predictors for pediculosis capitis were female gender $(\mathrm{OR}=6.02,95 \% \mathrm{Cl}=2.97-12.21)$, Indian ethnicity $(\mathrm{OR}=5.55,95 \%$ $\mathrm{Cl}=3.26-9.45)$, sibling of more than $5(\mathrm{OR}=2.72,95 \% \mathrm{Cl}=1.04-7.12)$ and contact with infested person $(\mathrm{OR}=2.42,95 \% \mathrm{Cl}=1.58-3.71)$. Conclusion: The prevalence of Pediculosis capitis among urban primary school children in Kuantan, Pahang is endemic (9.1\%) and predictors are female genders, Indian ethnicity, having siblings of more than 5 and contact with infested person. Hence, preventive measures are necessary to reduce the transmission of head lice among school children. 